\title{
COVID-19 y suspensión de patentes. Entre la fábula y la historia
}

\author{
$* * * *$ \\ Miguel A. Rapela \\ Centro de la Propiedad Intelectual, Facultad de Derecho, Universidad Austral \\ mrapela@austral.edu.ar
}

Recibido: 31 de mayo de 2021

Aceptado: 16 de junio de 2021

\section{Resumen}

A pesar de que la respuesta del sistema científico público y privado mundial a la necesidad de desarrollar vacunas contra la virosis de la COVID-19 ha sido extraordinaria y que los derechos de propiedad intelectual han jugado un papel fundamental en estos desarrollos, algunos Gobiernos y organizaciones no gubernamentales han presentado propuestas y pedidos para limitar, suspender y hasta prohibir estos derechos relacionados con vacunas para la COVID-19.

Una parte significativa de estas argumentaciones se ha basado en citar, como ejemplos proverbiales, los casos de las vacunas para erradicar la poliomielitis y la invención de los anticuerpos monoclonales, sosteniendo que los desarrolladores se rehusaron a patentar estas invenciones como gesto altruista para beneficio de la humanidad, garantizando amplio acceso y bajo costo.

Sin embargo, la revisión histórica de los desarrollos científicos de Jonas Salk y de Albert Sabin para las vacunas de la poliomielitis y de César Milstein (junto a Georges Köhler) para la invención de los anticuerpos monoclonales y su relación con las respectivas solicitudes de patentes no permite identificar voluntad de no patentar en dos casos ni una relación de causa-efecto en los tres casos. Justificar el pedido para limitar las patentes sobre vacunas para COVID-19 en estos tres casos históricos no solo carece de fundamento, sino que además omite que la falta de patentamiento provocó que dichas invenciones quedaran en el dominio público, siendo las compañías farmacéuticas y no las instituciones académicas las principales beneficiadas en términos económicos. La existencia de patentes sobre estas invenciones, por el contrario, les habría asegurado a sus desarrolladores derechos exclusivos para controlar las variables del mercado, incluyendo el precio de los 
productos, licenciar sus invenciones a quienes quisieran y aplicar mínimas regalías para redireccionarlas a círculos virtuosos de invención, desarrollo e innovación.

Palabras clave: COVID-19, vacunas, patentes, poliomielitis, anticuerpos monoclonales.

\title{
COVID-19 and Patent Waivers. Between Fable and History
}

\begin{abstract}
Even though the response of the world's public and private scientific system to the need to develop vaccines against COVID-19 virus has been extraordinary and that intellectual property rights have played a fundamental role in these developments, some governments and Non-Governmental Organizations have presented proposals and requests to limit, suspend or even prohibit these rights related to COVID-19 vaccines.

A significant part of these arguments has been based on citing, as proverbial examples, the cases of vaccines to eradicate poliomyelitis and the invention of monoclonal antibodies, arguing that the developers refused to patent these inventions as an altruistic gesture for the benefit of mankind, guaranteeing wide access and low cost.

However, the historical review of the scientific developments of Jonas Salk and Albert Sabin for the polio vaccines and of César Milstein (together with Georges Köhler) for the invention of monoclonal antibodies and their relationship with the respective patent applications, does not allow us to identify a desire not to patent in two cases, nor a cause-effect relationship in the three cases. Justifying the request to limit vaccine patents for COVID-19 in these three historical cases is not only unfounded, but also omits that the lack of patenting caused these inventions to remain in the public domain, with pharmaceutical companies and not academic institutions being the main beneficiaries in economic terms. The existence of patents on these inventions, on the contrary, would have assured their developers exclusive rights to control market variables including the price of products, license their inventions to whomever they wished and apply minimal royalties to redirect them into virtuous circles of invention, development and innovation.
\end{abstract}

Key words: COVID-19, vaccines, patents, poliomyelitis, monoclonal antibodies.

\section{COVID-19 e suspensão de patentes. Entre a fábula e a história}

\section{Resumo}

Embora a resposta do sistema científico público e privado global à necessidade de desenvolver vacinas contra a COVID-19 tenha sido extraordinária e os direitos 
de propriedade intelectual tenham desempenhado um papel fundamental nestes desenvolvimentos, alguns governos e organizaçôes não governamentais apresentaram propostas e pedidos para limitar, suspender ou mesmo proibir estes direitos relacionados com as vacinas para a COVID-19.

Uma parte significativa destes argumentos tem sido baseada na citação, como exemplos proverbiais, dos casos de vacinas para erradicar a poliomielite e a invenção de anticorpos monoclonais, argumentando que os criadores recusaram patentear estas invençóes como um gesto altruísta em benefício da humanidade, garantindo um amplo acesso e baixo custo.

Contudo, a revisão histórica dos desenvolvimentos científicos de Jonas Salk e Albert Sabin para as vacinas contra a poliomielite e de César Milstein (juntamente com Georges Köhler) para a invenção de anticorpos monoclonais e a sua relaçáo com os respectivos pedidos de patente, náo permite identificar a vontade de náo patentear em dois casos, nem uma relação causa-efeito nos três casos. Justificar o pedido de limitar as patentes de vacinas para a COVID-19 nestes três casos históricos não só não tem fundamento, como também omite que a falta de patenteamento fez com que estas invençôes permanecessem no domínio público, sendo as empresas farmacêuticas e não as instituições académicas os principais beneficiários económicos. A existência de patentes sobre estas invençôes, pelo contrário, teria assegurado aos seus criadores direitos exclusivos para controlar as variáveis de mercado, incluindo o preço dos produtos, licenciar as suas invençôes a quem desejassem e aplicar royalties mínimas para as reorientar para círculos virtuosos de invenção, desenvolvimento e inovação.

Palavras-chave: COVID-19, vacinas, patentes, poliomielite, anticorpos monoclonais.

\section{Introducción ${ }^{1}$}

Línea de tiempo: 31/12/2019, la oficina china de la Organización Mundial de la Salud (OMS) recibe la notificación de la aparición de cuatro casos de neumonía de etiología desconocida en la ciudad de Wuhan (provincia de Hubei). Día 12/01/2020, los investigadores chinos dan a conocer la secuencia genética del virus SARS-CoV-2, responsable de la virosis de COVID-19. Día 11/03/2020, la OMS informa de la caracterización de la COVID-19 como una pandemia. Día 11/04/2020, la OMS confirma más de un millón de casos de COVID-19 en todo el mundo. Día 13/04/2020, la OMS

1 El autor desea expresar su mayor agradecimiento al Dr. Jorge A. Goldstein, director del Estudio Sterne Kessler Goldstein \& Fox de los Estados Unidos, por la lectura crítica del original y sus valiosos aportes y sugerencias. 
publica una declaración suscrita por 130 científicos, donantes y fabricantes de todo el mundo en la que se comprometen a trabajar con la OMS para acelerar el desarrollo de una vacuna contra la COVID-19. Día 01/07/2020, la OMS presenta el diseño de ensayo global, internacional y adaptable para vacunas y la creación de un comité para supervisar las etapas de ensayos preclínicos y clínicos. Día 15/07/2020, se lanza el Compromiso COVAX para el acceso rápido, justo y equitativo a las vacunas contra la COVID-19 en todo el mundo. Día 01/10/2020, la OMS abre la primera convocatoria de manifestaciones de interés para los fabricantes de vacunas contra la COVID-19. Día 31/12/2020, la OMS valida la primera vacuna contra la COVID-19. Día 29/04/2020, se llega al primer billón de vacunas producidas (Organización Mundial de la Salud, 2020). Día 28/05/2021, la OMS informó que existían 184 vacunas candidatas en etapa preclínica y 102 en etapa clínica. De estas últimas, 4 están en Fase 4, 18 en Fase 13, 7 en Fase 2/3, 9 en Fase 2, 28 en Fase 1/2 y 35 en Fase 1 (Organización Mundial de la Salud, 2021). Se estima que para fines de 2021, la cantidad de vacunas producidas estará entre 12 y 14000 millones de dosis, y UNICEF hace una estimación de 39200 para 2022 (Jiménez Nácher, 2021). Esta tremenda respuesta del sistema científico público y privado internacional en tan corto tiempo y de sus mecanismos de cooperación fue calificada por la revista Nature como un logro sin precedentes (Kreia, 2021).

Para este logro de la ciencia y de la inteligencia, la propiedad intelectual, y en particular las patentes farmacéuticas, jugaron un rol fundamental. Desde la perspectiva de este análisis, la relación entre la idea creativa, invención e innovación funcionó de manera altamente satisfactoria y la propiedad intelectual fue el factor determinante. A pesar de ello, el problema central a la fecha de redacción de este artículo es que la demanda de vacunas para COVID-19 supera significativamente a la oferta, la cual está limitada por la escasez de insumos, sumada al rápido agotamiento de los stocks de dosis (Lehtinen y Rapela, 2021).

En este altamente sensible contexto, no fue extraño que se alzaran voces de algunos Gobiernos y de organizaciones no gubernamentales $(\mathrm{ONG})$ con propuestas y pedidos para limitar, suspender y hasta prohibir los derechos de propiedad intelectual (DPI) relacionados con medicamentos para la COVID-19. Estos grupos les atribuyen 
a los DPI parte o la totalidad de la responsabilidad de la falta de vacunas. Las propuestas tomaron un canal institucional ante la OMS mediante un proyecto de decisión presentado por India y Sudáfrica, que ha tenido la adhesión de distintos actores gubernamentales y, particularmente, la declaración del presidente de los Estados Unidos y de su Departamento de Estado, en relación con que dicho país entiende que se deben suspender las patentes mientras dure la pandemia. La iniciativa de la India y Sudáfrica no fue solo para solicitar la suspensión de las patentes sobre COVID-19, sino para liberar todo el Capítulo II del ADPIC (OMS, 2020).

Una parte significativa de las argumentaciones se ha basado en citar reiteradamente los casos de las vacunas para erradicar la poliomielitis, aduciendo que los desarrolladores (Jonas Salk y Albert Sabin) se rehusaron a patentar estos extraordinarios logros como gesto altruista para beneficio de la humanidad, y que esta decisión fue fundamental para erradicar la enfermedad en relativamente poco tiempo y a bajo costo. ${ }^{2}$ Asimismo, se ha traído la misma referencia en relación con la invención de los anticuerpos monoclonales de César Milstein y Georges Köhler.

En este artículo se presenta una revisión histórica de los desarrollos científicos de Jonas Salk y de Albert Sabin para las vacunas de la poliomielitis y de César Milstein (junto a Georges Köhler) para la invención de los anticuerpos monoclonales y la falta de presentación de las respectivas solicitudes de patentes. No es propósito analizar la argumentación de dichas faltas, las cuales son tomadas como hechos fácticos. El objetivo es esclarecer, exclusivamente para estos tres casos, si la falta de patentamiento se debió a las convicciones o determinaciones personales de los investigadores o si fue por causas ajenas a sus voluntades y el devenir de estos hechos, en particular las solicitudes y concesiones de patentes de los desarrollos posteriores a las invenciones originales. En definitiva, se trata de establecer si los pedidos para limitar, suspender y hasta prohibir los DPI relacionados con medicamentos para la COVID-19 pueden razonablemente justificarse utilizando los antecedentes de estos tres casos históricos.

2 Una búsqueda en internet con los términos "covid Salk Sabin patent" da como resultado 70300 sitios de referencia. 


\section{Jonas Salk}

Jonas Edward Salk (1914-1995) fue un investigador médico y virólogo estadounidense, mundialmente reconocido por haber liderado el equipo que desarrolló la primera vacuna segura y efectiva contra la poliomielitis.

Hasta 1955, cuando se presentó la vacuna Salk, la poliomielitis se consideraba el problema de salud pública más peligroso en los Estados Unidos de posguerra. La poliomielitis es una enfermedad altamente contagiosa producida por un poliovirus, que invade el sistema nervioso de una persona produciendo dolor muscular, atrofia, parálisis flácida e incluso la muerte. Si bien se han dado casos en personas adultas, el poliovirus afecta por lo general a los nińos menores de 5 años. El poliovirus ingresa en el cuerpo por vía oral, mediante alimentos o agua contaminados con la materia fecal de una persona infectada con el virus. No existe tratamiento específico para la poliomielitis, pero puede prevenirse por medio de la vacunación. En Argentina no hay casos desde 1984, mientras que en América el último caso fue en 1991 y la región fue declarada libre de la enfermedad en 1994. En el resto del mundo, actualmente hay casos solo en dos países de Asia: Pakistán y Afganistán (Bernardo, 2015; Ministerio de Salud, 2021).

En el año 1947, Jonas Salk comenzó a trabajar en la Escuela de Medicina de la Universidad de Pittsburgh y, un año más tarde, lideró un proyecto creado por la Fundación Nacional para la Parálisis Infantil para determinar el número de tipos diferentes de virus de la poliomielitis. Con certeza, Salk captó la oportunidad para desarrollar una vacuna contra la polio dedicándose a ello en los siguientes siete años. Su proyecto fue de impresionantes dimensiones y contó con aportes monetarios voluntarios de millones de personas. Después de inocular con éxito a miles de monos, Salk comenzó, en 1952, el arriesgado paso de probar la vacuna en humanos. Además de administrar la vacuna a más de 1800000 niños en edad escolar que formaron parte del comité de prueba, también se inyectó a sí mismo, a su mujer y a sus tres hijos. En este proyecto, por primera vez, los investigadores utilizaron el método de doble ciego, ahora estándar en los análisis clínicos, en el que ni el paciente ni la persona que administra la inoculación conocen si era una vacuna o un pla- 
cebo. El 12 de abril de 1955, por medio de una transmisión radial a nivel nacional, Salk anunció el éxito de las primeras pruebas de la vacuna en humanos, convirtiéndose de inmediato en una figura de dimensión descomunal en los Estados Unidos y de enorme prestigio internacional (Salk Institute for Biological Studies, 2021).

Fue justamente en esa misma transmisión radial que el muy conocido, en ese momento, periodista de la CBS Edward Morrow le preguntó a Salk a quién le pertenecía la patente. "Bueno, al pueblo, diría yo", dijo Salk en vista de las millones de donaciones benéficas recaudadas por la denominada "March of Dimes", que financiaron la investigación y las pruebas de campo de la vacuna. "No hay ninguna patente. ¿Podrías patentar el sol?”. 3

Nunca se sabrá si Salk tenía prevista esta respuesta o fue la salida espontánea ante una pregunta inesperada. Lo concreto es que su frase se convertiría en icónica y en el estandarte hasta el día de hoy de todos los grupos que apoyan la suspensión o incluso la eliminación de patentes en temas relacionados con medicina humana. ${ }^{4}$

Sin embargo, el trasfondo es diferente. Especialistas como el Dr. Robert Cook-Deegan, ${ }^{5}$ que han analizado todo el devenir de aquel proyecto (Cook-Deegan como se cita en Kinsella, 2006), o libros completos, como el de Jane S. Smith (1990), puntualizan que Salk o ignoraba o no mencionó que los abogados de la National Foundation for Infantile Paralysis (Fundación Nacional para la Parálisis Infantil) habían estudiado la posibilidad de patentar la "vacuna Salk", llegando a la conclusión de que no era una invención patentable debido a la pérdida del criterio de novedad.

Si bien Salk en su conferencia dio a entender que la decisión fue moral, Jane Smith (1990) señala que, creyera o no el propio Salk lo que le dijo a Murrow, la idea de patentar la vacuna había sido analizada directamente y se tomó la decisión de no solicitar una patente, principalmente porque no se obtendría. Aunque es difícil entender

3 "Well, the people, I would say". "There is no patent. Could you patent the sun?".

4 Una búsqueda en la web de la frase “¡Podrías patentar el sol?” arroja 11900 resultados, y la búsqueda de "Could you patent the sun?” arroja 74800000 resultados.

5 Robert Cook-Deegan, MD Director, Center for Genome Ethics, Law, and Policy Institute for Genome Sciences and Policy, Duke University, Durham. 
por qué los abogados de la Fundación al menos no lo intentaron, lo cierto es que antes -o en forma paralela a la renuncia de la solicitud de patente- la Fundación de Salk ya había adelantado la formulación y los procesos de producción de la vacuna a varias empresas farmacéuticas y comprometido a cederla gratuitamente, lo cual con seguridad hubiese afectado negativamente el requisito de novedad y, probablemente, comprometido el de altura inventiva (Intellectual Property Expert Group, 2021).

Sin embargo, agrega Smith (1990), nunca sabremos si la Fundación Nacional sobre la Parálisis Infantil o la Universidad de Pittsburgh habrían patentado la vacuna si hubieran podido, pero la simple interpretación moral que se suele aplicar a este caso no se ajusta a la verdad histórica.

Al no existir una patente, la "vacuna Salk" pasó al dominio público, imposibilitando que el instituto de Salk pudiese recuperar regalía alguna de las enormes cifras producto de su comercialización. Una estimación de estas regalías realizada por la revista Forbes fue de 7000 millones de dólares para el año 2012 (How Much Money Did Jonas Salk..., 2012). En síntesis, el no patentamiento de la vacuna Salk no solamente fue en beneficio económico de las empresas farmacéuticas involucradas, sino que además no impidió que decenas de vacunas posteriores se desarrollaran y fuesen protegidas por patentes. ${ }^{6}$ Especulando se puede suponer además que quizás el propio Jonas Salk no quiso repetir los hechos y, años más tarde, patentaría invenciones para otras enfermedades altamente sensibles, como el $\mathrm{HIV}^{7}$ (Esparza, 2006).

6 Por ejemplo, una búsqueda con la combinación de palabras "Salk, Multivalent Vaccine Comosition, Poliomyelitis" en el Patenscope del portal de la Organización Mundial de la Propiedad Intelectual (WIPO, por sus siglas en inglés) detalla las siguientes solicitudes de patentes de Composiciones de Vacunas Polivalentes desarrolladas con los antígenos de la vacuna Salk original, todas con el idéntico título de "Multivalent Vaccine Composition": Patentes 3503917; WO/2018/037365; 110691611; 201621029037; 3032901; 2017316768; 20190175722; 201917010003; 1/2019/500404; 751127.

7 En 1987, Jonas Salk propuso el uso de preparaciones inactivadas del VIH 


\section{Albert Sabin}

Albert Bruce Sabin (1906-1993) fue un médico virólogo polaco nacionalizado estadounidense. Tras obtener su grado de médico por la New York University, se radicó en 1939 en el Hospital Infantil de Cincinnati, donde comenzó sus estudios sobre la poliomielitis.

Si bien el desarrollo de la vacuna por Salk había constituido un paso trascendental para el control de la virosis, esta tenía dos inconvenientes. El primero de ellos es que era de aplicación intramuscular, lo cual implicaba la necesidad de contar con personal especializado para ello. El segundo inconveniente es que la vacuna Salk era a base de poliovirus inactivados y no protegía a las personas de ser portadoras del virus causante de la polio.

El aporte de Sabin a ambos inconvenientes fue trascendental. Después de extensas pruebas en las que se utilizaban monos y chimpancés, en 1955 Sabin tomó la decisión de probar en seres humanos y solicitó sujetos voluntarios entre los reclusos del Reformatorio Industrial Federal de Chillicothe (Ohio) e incluso probó la vacuna con sus propias hijas. Pero dado el enorme respaldo que el Gobierno de los Estados Unidos tenía con la vacuna Salk, Sabin tuvo que dirigirse a la Unión Soviética y a México para realizar ensayos a gran escala. Finalmente, en el año 1957, Sabin logró demostrar los beneficios de su vacuna, la cual se impuso en Estados Unidos y en la OMS (Suess, 2019). La vacuna de Sabin era de vía oral y se suministraba a los niños en un terrón de azúcar, lo cual implicaba que su aplicación carecía de la necesidad de contar con personal especializado, convirtiéndola de hecho en una herramienta sumamente eficaz en regiones faltas de infraestructura adecuada. Además, a diferencia de

como enfoque terapéutico para la inmunización de pacientes infectados, lo que condujo al desarrollo de Remune ${ }^{\varpi}$, un inmunógeno inactivado y empobrecido en gp120, fabricado por Immune Response Corporation (Carlsbad, California). Más adelante, en 1996, la empresa inició ensayos clínicos a gran escala, que se interrumpieron en 1998. Figurando como único inventor, Jonas Salk solicitó la patente de la invención bajo el procedimiento del Tratado de Cooperación de Patentes, (Patent Cooperation Treaty, PCT). Número de Publicación WO/1994/002171; fecha 3 de febrero de 1994; Aplicación Internacional PCT /US1993/006820; fecha de aplicación internacional 20 de julio de 1993. 
la vacuna Salk, la vacuna Sabin estaba basada en virus atenuados, los cuales, al pasar por el tracto gastrointestinal, no solo protegían a los individuos de contraer la polio, sino que también evitaba contagiar a otros (Bernardo, 2015).

A diferencia de lo sucedido con la "vacuna Salk", no existe registro alguno que indique que Sabin haya intentado patentar su vacuna, aunque no se puede descartar que los especialistas de la Universidad hayan llegado a la misma conclusión de no patentabilidad por falta de novedad, como el caso de la vacuna de Salk. Lo cierto es que Sabin insistió en que tanto la vacuna como su administración fueran gratuitas y aproximadamente 100 millones de niños europeos recibieron la vacuna, mientras que otros 100 millones de estadounidenses de todas las edades fueron vacunados a principios de la década del 60. Se calcula que la vacuna evitó 500 mil muertes y 5 millones de casos de poliomielitis paralítica (Friedman, 2020).

Sin embargo, al igual que la "vacuna Salk", el no patentamiento dejó el desarrollo en el dominio público. Pero, en este caso, las cosas evolucionaron en forma diferente. Los poliovirus son genéticamente inestables y pierden mutaciones atenuantes al replicarse en el tracto gastrointestinal humano, al tiempo que ganan aptitud y adquieren la capacidad de propagarse en entornos con bajas tasas de inmunización y una elevada fuerza de infección debido a las malas condiciones. Para mitigar los riesgos de la aparición de variantes del virus, la Iniciativa de Erradicación Mundial de la Poliomielitis ${ }^{8}$ comenzó una estrategia de retirada gradual de las tres cepas Sabin originales de uso mundial, comenzando con la sustitución coordinada de la vacuna trivalente por la bivalente. La necesidad de producir suficientes vacunas para inmunizar a los más de 100 millones de niños que viven en países afectados generó una oportunidad para que nuevos fabricantes de vacunas ingresaran en el mercado mundial, incluidos los de los países en desarrollo. La OMS estimó que en los próximos 5 a 7 años estarán disponibles varias vacunas nuevas, algunas como producto independiente y otras combinadas en una formulación

8 En 1988, la 41 a Asamblea Mundial de la Salud, a la que asistieron delegados de 166 Estados miembros, adoptó una resolución sobre la erradicación mundial de la poliomielitis que marcó la creación de la Iniciativa de Erradicación Mundial de la Poliomielitis, encabezada por la OMS. 
hexavalente con toxoide diftérico, toxoide tetánico, vacuna de células enteras contra la tos ferina, vacuna contra la hepatitis B y antígenos de Haemophilus influenzae tipo B (Modlin y Chumakov, 2020). El punto fundamental ha sido el desarrollo de nuevas vacunas a partir de la Sabin original a precios más reducidos, introduciendo mayor eficiencia en el procesamiento o utilizando adyuvantes o dosis fraccionadas (Hamidi y Bakker, 2012). Todas estas nuevas vacunas disponen de solicitudes de patentamiento o ya están patentadas. ${ }^{9}$

En síntesis, si bien la vacuna Sabin original nunca fue patentada, posiblemente gran parte de las "vacunas Sabin" de segunda generación que hoy se comercializan sí lo estén. De acuerdo con informes del año 2016, Sanofi Pasteur y Bilthoven Biologicals/Serum Institute of India son las dos empresas a las que UNICEF les adjudicó el suministro de las nuevas vacunas Sabin. Según informes de UNICEF, Bio Farma (Indonesia), GlaxoSmithKline (GSK) (Reino Unido) y Sanofi Pasteur (Francia) son los únicos fabricantes de vacunas Sabin a granel. Otros actores del mercado son Sinovac Biotech Ltd., IPOL y Aventis Pasteur, Merck \& Co., Bibcol, Pfizer, Beijing Tiantan Biological, BioMed, Panacea Biotec Ltd. y Adithya Vaccine Pharma (Miles, 2016).

9 Una búsqueda con la palabra "Sabin" en el Patenscope del portal de la Organización Mundial de la Propiedad Intelectual arroja 2545 resultados positivos. Los cinco que figuran en primer lugar son: 1. Patente 104371979 "Sabin strain poliovirus Type II monoclonal antibody application thereof"; 2. Patente 1020040050346, "Recombinant Sabin Type 1I poliovirus vector and brecombinbant vaccine composition against poliovirus"; 3. Patente 0966539, "Replication competent recombinant Sabin Type 1 starin of poliovirus"; 4. Patente 104371980, "Sabin strain poliovirus Type III monoclonal antibody and application thereof"; 5. Patente WO/1999/007859, "Repicationcompetent recombinant Sabin Type 1 strain of poliovirus". Fuera de este portal, algunos otros ejemplos de patentes son: Patente WO 2007/007344 Al, "Inactivated poliomyelitis vaccine derived from Sabin strain of polio virus" (2004); Patente US 2008/0193478 A1, "Inactivated Poliomyelitis Vaccine Derived From Sabin Strain Of Polio Virus" (2008); Patente US 9.402,892 B2, "Inactivated Poliovaccine" (2016); Patente CA 2664799, "Vaccin de Salk (IPV) et contre la diphterie, la coqueluche et le tetanus" (1989); Patente EP 1793852 A1 20070613, "Inactivated Poliomyelitis vaccine derived from Sabin strain of Polio Virus" (2007); Patente CN 104371979, "Sabin strain poliovirus type II monoclonal antibody and application thereof" (2014); Patente CA 2660375, “Attenuated Polioviruses” (2006). 
Excepto las contribuciones voluntarias, el instituto de Sabin no recibió ningún tipo de reconocimiento económico contractual.

\section{César Milstein}

César Milstein (1927-2002) fue un doctor en Química argentino y el último Premio Nobel de esta nacionalidad, en 1984. Nació en Bahía Blanca, provincia de Buenos Aires, donde realizó hasta el colegio secundario. Luego se trasladó a Capital Federal para estudiar en la Universidad de Buenos Aires: se graduó de licenciado en Ciencias Químicas en la Facultad de Ciencias Exactas y Naturales en 1952 y terminó su doctorado en 1956. Su posdoctorado lo realizó en la Universidad de Cambridge y regresó a Argentina en 1961 para hacerse cargo de la División de Biología Molecular del Instituto Nacional de Microbiología. Tras el golpe militar de 1962, decidió regresar a Inglaterra, donde transcurriría el resto de su vida profesional (Academia Nacional de Medicina, 2003).

En la Universidad de Cambridge, junto a Georges Köhler, inventó la técnica de creación de hibridomas, líneas celulares híbridas obtenidas mediante la fusión de un linfocito B capaz de producir un anticuerpo específico de interés con una línea celular de mieloma o linfocito B canceroso. La hibridoma resultante es una línea celular inmortal capaz de producir el anticuerpo monoclonal de interés, que puede recuperarse del medio de cultivo. El paso de los anticuerpos policlonales a la exquisita especificidad de los anticuerpos monoclonales fue un verdadero cambio de paradigma médico al ofrecer la posibilidad de crear nuevos reactivos para la administración in vivo de fármacos terapéuticos o toxinas en lugares celulares definidos y para mejorar los métodos de diagnóstico (Rapley, 1995).

Lo que ocurrió entre la invención y la publicación de la investigación en la revista Nature terminó constituyéndose en uno de los casos paradigmáticos de apreciación equivocada de propiedad intelectual.

En numerosas ocasiones se ha sostenido que Milstein no patentó su invención porque pensaba que su trabajo intelectual era propiedad de la humanidad y así debía ser el legado a posteriores generacio- 
nes. ${ }^{10}$ Sin embargo, esto dista mucho de lo que realmente sucedió. Según los análisis de Tansey et al., (1997), del Medical Research Council (MRC) (1997) y de la Universidad de Cambridge (2002), ${ }^{11}$ en julio de 1975 y antes de la publicación en Nature, Milstein hizo una presentación sobre los anticuerpos monoclonales en una reunión interna del MRC (Consejo de Investigación Médica). Uno de los asistentes a la reunión fue Anthony Vickers, funcionario del MRC. Tras la presentación, Vickers le informó a Milstein y a Köhler que él consideraba que el trabajo podría ser patentable y les pidió copias del artículo a publicar en Nature, a lo cual accedieron. Vickers informó a la National Research Development Corporation (NRDC), el organismo responsable de patentar invenciones de MRC, para ver si podían presentar una patente. La acción debía ser rápida porque la ley de patentes británica no permitía la divulgación de ningún trabajo, como la publicación de un artículo antes de presentar una solicitud de patente. La respuesta llegó en forma de una carta del NRDC, que puede ser consultada en internet (con fecha 7 de octubre de 1976). El personal del NRDC dejó claro que si bien reconocían el posible valor médico y comercial de la tecnología de hibridoma, no podían "identificar ninguna aplicación inmediata", por lo cual consideraban que no había que tomar ninguna medida para solicitar la patente. En términos patentarios, la conclusión fue que no existía aplicación industrial. ${ }^{12}$

El error de apreciación de los técnicos del NRDC fue fenomenal. La invención de Milstein y Köhler rápidamente se perfeccionó para llevarla a escala industrial y el negocio de la síntesis de anticuerpos monoclonales adquirió cifras multimillonarias, calculadas en más de 100 mil millones de dólares para 2023, de la mano de Merck \& Co.

10 Entre otros, ver: Bär (2018); Vercesi (2021). Es notable también en estas y varias otras citas que se confunde "descubrimiento" con "invención” en lo relativo a los anticuerpos monoclonales.

11 Apreciaciones similares han sido comentadas, por ejemplo, por: González-Fernández y Díaz de Espada (2011); Castelli y Leiva (2019)

12 Textualmente, el NRDC expresó: "It is certainly difficult for us to identify any immediate practical applications which could be pursued as a commercial venture, even assuming that publication had not already occurred" (Eichmann, 2005, p. 94). 
Inc., Novartis AG, Abbot y Johnson \& Johnson Services, Inc., principales empresas farmacéuticas proveedoras.

Este error del NRDC de no patentar la técnica de Milstein y Köhler se convirtió en objeto de enorme controversia en Inglaterra a fines de la década de 1970 . Una de las críticas más vehementes de la falta de patente de la técnica de anticuerpos monoclonales fue la de Margaret Thatcher, primera ministra en ese momento y química de formación, por lo cual se conformó una comisión para analizar lo sucedido. El informe exculpó al NRDC y gran parte de la culpa de no patentar recayó sobre los hombros de los propios científicos. Esto indignó a Milstein, en particular por el siguiente párrafo:

Parece que hay una falta de conciencia en la práctica de las obligaciones de los beneficiarios del dinero del gobierno y de los derechos del NRDC. Esto debe ser remediado. Nos preocupa que la falta de apreciación del NRDC, particularmente por científicos jóvenes, pueda continuar dando lugar a situaciones como la que ocurrió con los anticuerpos monoclonales, donde la protección por patente no se buscó con la suficiente antelación y se redujo la ventaja británica. (como se cita en Medical Research Council, 1997) ${ }^{13}$

El enojo de Milstein fue significativo e incluyó una carta con su firma dirigida a Margaret Thatcher, la cual puede ser consultada en internet. En primer lugar, por el hecho de que claramente él no había sido parte de la disposición de no patentar, sino que eso había sido decisión del NRDC. En segundo lugar, el famoso artículo de Nature, que llevaría a ambos investigadores al Premio Nobel, ya anticipaba con mediana precisión que la invención disponía de aplicación industrial. ${ }^{14}$ No obstante, es necesario apuntar que, en ese entonces, no había en la comunidad científica británica un sentimiento a favor

13 "There appears to be a lack of awareness in practice of the obligations on recipients of government money and of the rights of the NRDC. This must be remedied. We are concerned that a lack of appreciation of the NRDC, particularly by young scientists, may continue to result in situations such as that which occurred over monoclonal antibodies where patent protection was not sought early enough and British advantage was reduced".

14 Dice textualmente el artículo de Kohler y Milstein (1975): "Tales células pueden 
del patentamiento. En muchos sentidos, la actitud laxa de Milstein fue un reflejo de la aversión más general de la comercialización dentro del Laboratorio de Biología Molecular en la década de 1970. La situación estaba reforzada por el hecho de que los científicos que trabajaban en los laboratorios biomédicos financiados por el Gobierno británico no tenían derecho a ninguna regalía por patentar sus innovaciones en ese momento, las cuales quedaban enteramente a favor de esa institución. Este sentimiento solo comenzó a cambiar en la década de 1980, cuando el MRC estableció un nuevo esquema que permitió el intercambio de regalías con los inventores.

Finalmente, idéntico a los dos casos anteriores, el no patentamiento de la invención de Milstein no impidió las solicitudes y concesiones posteriores de miles de patentes sobre anticuerpos monoclonales. ${ }^{15}$

\section{Conclusiones}

Los tres casos analizados disponen de características propias. Las vacunas de Salk y de Sabin respondieron a necesidades de salud pública mundial, lo cual las hace sustancialmente similares al caso de las vacunas contra la COVID-19, mientras que los anticuerpos monoclonales de Milstein configuraron una invención de cambio de paradigma en medicina. Pero los tres casos disponen de semejanzas importantes. No se solicitó una patente para proteger a la "vacuna Salk" porque los profesionales de la Fundación Nacional para la Parálisis Infantil de los Estados Unidos consideraron que no reunía las condiciones sustantivas de novedad, de altura inventiva o ambas y, por lo tanto, la invención no era materia patentable. La "vacuna Sabin" original tampoco fue objeto de una solicitud de patente por la institución oficial, pero la gran mayoría de los desarrollos y mejoras de esta sí lo fueron, existiendo miles de solicitudes o patentes concedidas. La patente de los anticuerpos monoclonales no fue solicitada porque los

crecer in vitro en cultivos masivos para proporcionar anticuerpos específicos. Tales cultivos podrían ser valiosos para el uso médico e industrial” (p. 497).

15 Por ejemplo, una búsqueda con la combinación de palabras "Monoclonal Antibodies" en el Patenscope del portal de la Organización Mundial de la Propiedad Intelectual arroja 28481 presentaciones. 
profesionales del National Research Development Corporation, organismo responsable de patentar invenciones del Medical Research Council, consideraron que no reunía la condición sustantiva de aplicación industrial y, por lo tanto, la invención no era patentable.

Además, los tres casos son similares en cuanto a que la falta de protección por patente de las invenciones hizo que quedaran en el dominio público, lo cual fue ágilmente utilizado por diversas compañías farmacéuticas para generar negocios legales de cientos de miles de millones de dólares que no les redituaron beneficios contractuales a los genuinos inventores. Dada la enorme relevancia de estas tres invenciones, es imposible no señalar que la divulgación hubiese sido igualmente eficiente con o sin patentes, pero, en el primer caso, la equidad y el equilibrio habrían sido significativamente más justos.

Más allá de las respetables convicciones particulares de los científicos involucrados, la revisión histórica de los casos de Salk y Milstein revela inequívocamente que las instituciones en las que trabajaban analizaron la opción de patentar. Si esto finalmente no se llevó a cabo no fue por la falta de intención de patentar, sino por una presunta carencia de elementos sustantivos de los requisitos de patentabilidad, lo cual es completamente diferente. En el caso de Sabin, no existe prueba alguna de que la invención se haya querido patentar, pero este hecho no impidió que gran parte de todos los desarrollos posteriores de la vacuna quedaran bajo protección patentaria, con menor ámbito reivindicado, lo que igualmente sucedió con las invenciones de Salk y Milstein. Bajo este análisis, los pedidos de limitar, suspender o prohibir los derechos de propiedad intelectual sobre los medicamentos para la COVID-19 justificándolos en estos tres antecedentes históricos carecen de fundamento sólido.

La icónica frase de Jonas Salk "No hay ninguna patente. ¿Podrías patentar el sol?" no se debe extractar de su momento histórico ni echar culpas por ello. En aquella época, patentar invenciones que hoy calificaríamos de "biotecnológicas" no solo era algo raro, sino que además era incipiente comprender la diferencia entre invención y descubrimiento en materia viva, lo cual es manifiesta en la frase aludida. Por ejemplo, para el sistema patentario de Estados Unidos debieron transcurrir décadas hasta que se estableció claramente que microorganismos creados por el hombre y no prexistentes en la na- 
turaleza son materia patentable (caso Chakrabarty ${ }^{16}$ ), mientras que genes aislados preexistentes en cualquier organismo no lo son (caso Myriad Genetics ${ }^{17}$ ), principios que son prácticamente materia común en todo el mundo. En el presente, estas abstracciones ya no tienen lugar. La biología comercial ha brindado numerosos ejemplos concretos de beneficios para la humanidad, y tanto en el mundo empresario como académico de los países desarrollados se dispone de un completo conocimiento del componente equitativo que tienen las patentes y de su relevancia para los procesos de invención, desarrollo e innovación.

Queda analizar la cuestión que estamos tratando, pero en sentido inverso; ¿Qué habría ocurrido si estas tres invenciones se hubiesen patentado? Aplicando el alcance conferido por el artículo $28 \mathrm{del}$ Acuerdo sobre los ADPIC, sus titulares hubiesen gozado de los derechos exclusivos de impedir que terceros, sin su consentimiento, realicen actos de fabricación, uso, oferta para la venta, venta o importación y, asimismo, hubiesen dispuesto del derecho de ceder, transferir o concertar contratos de licencia con sus invenciones (Acuerdo sobre los Aspectos de los Derechos de Propiedad Intelectual relacionados con el Comercio, 2021). Dicho de otro modo, habrían sido "sobera-

16 Diamond v. Chakrabarty, 447 U.S. 303 (1980) (disponible en: https://supreme.justia.com/cases/federal/us/447/303/). Este histórico antecedente jurisprudencial en votación muy ajustada no solo le abrió la puerta al patentamiento de materia viva creada por el hombre, sino que también acuñó una frase célebre. La Suprema Corte de los Estados Unidos consideró que es materia patentable "cualquier cosa bajo el sol hecha por el hombre". Muchos analistas consideran que el armado de esta conclusión contiene una taxativa alusión a la frase de Jonas Salk.

17 Association for Molecular Pathologyv. Myriad Genetics, Inc., 569 U.S. 576 (2013) (disponible en: https://supreme.justia.com/cases/federal/us/569/576/). El 13 de junio de 2013, la Suprema Corte de los Estados Unidos dictaminó por unanimidad que "un segmento de $\mathrm{ADN}$ que se produce de forma natural es un producto de la naturaleza y no es patentable por el mero hecho de haber sido aislado". Esto invalidó las patentes de la compañía Myriad sobre los genes BRCA1 y BRCA2 relacionados con el cáncer de mama. Sin embargo, la Suprema Corte sostuvo que la manipulación de un gen para crear algo que no se encuentra en la naturaleza -como una cadena de ADN complementario producida sintéticamente $(\mathrm{ADNc})$ - podía ser materia patentable. 
nos" sobre el alcance de su invención protegida y podrían haber aplicado una política propia para el desarrollo, licenciamiento, venta o distribución (Rapela y Lehtinen, 2021). Asimismo, en caso de suceder una carencia del producto por falta de calidad, cantidad o precio excesivo, se habría podido solucionar aplicando las provisiones del artículo 31 del ADPIC sobre licencias obligatorias (Rapela y Schötz, 2020). Al no haber patente, el producto quedó en el dominio público y, por lo tanto, el beneficio fue exclusivamente para las compañías farmacéuticas que fueron capaces de llevar la innovación al mercado.

Además, en caso de que estas invenciones hubieran estado protegidas por patente, el precio del producto hubiese estado controlado por las instituciones académicas desarrolladoras y, obviamente, sujetas a las leyes de la competencia y antitrust. Si el fin altruista hubiese sido el de abaratar al máximo el precio del producto y que este se produjese bajo normas de calidad en el máximo número posible de empresas, se habría podido hacer sin ningún tipo de impedimento. En otras palabras, en ninguna circunstancia la hipotética existencia de derechos de propiedad intelectual habría provocado un aumento desmesurado del precio o carencia del producto, a no ser que eso fuese por la propia decisión o por una falla de la política y estrategia de licenciamiento de la institución desarrolladora.

Argumentar que la remediación a la poliomielitis, el costo accesible de estas vacunas y la amplia disponibilidad de anticuerpos monoclonales son consecuencia de la no existencia de patentes es una fábula que no se condice con estos tres antecedentes históricos disponibles.

Por el contrario, la existencia de patentes sobre estas invenciones les habría asegurado a sus desarrolladores derechos exclusivos para controlar las variables del mercado, incluyendo el precio de los productos, licenciar sus invenciones a quienes quisieran y aplicar mínimas regalías para redireccionarlas a círculos virtuosos de invención, desarrollo e innovación. En síntesis, habría sido la aplicación de una de las principales justificaciones del derecho de patentes, el quid pro quo, que considera a la patente como un intercambio entre el inventor y el público. 


\section{Bibliografía}

Academia Nacional de Medicina. (2003). César Milstein. https://anm.edu.ar/cesar-milstein/.

Acuerdo sobre los Aspectos de los Derechos de Propiedad Intelectual relacionados con el Comercio. (2021). Sección 5, Patentes, Artículo 28, Derechos conferidos. Acuerdo sobre los Aspectos de los Derechos de Propiedad Intelectual relacionados con el Comercio (ADPIC). Organización Mundial del Comercio. https:/www. wto.org/spanish/docs_s/legal_s/31bis_trips_04c_s.htm\#Footnote6.

Bär, N. (2018). El combustible del genio. Noticias UBA. http://www.uba.ar/noticiasuba/nota.php?id=20740.

Bernardo, A. (26 de agosto de 2015). ¿Por qué Jonas Salk no quiso patentar vacuna contra la polio? Hipertextual. https://hipertextual.com/2013/08/patentar-vacuna-contra-polio.

Castelli, S. y Leiva, M. C. (16 de octubre de 2019). Inventor sin invento. Comercio y Justicia. https://comercioyjusticia.info/opinion/inventor-sin-invento/.

Eichmann, K. (2005). The Patent Disaster. En Kohler's Invention (pp. 90-98). Springer Science.

Esparza, J. (2013). A brief history of the global effort to develop a preventive HIV vaccine. Vaccine, 31(35), 3502-3518. https://doi.org/10.1016/j.vaccine.2013.05.018.

Friedman, A. (2021). Albert Sabin. http://www1.biologie.uni-hamburg.de/b-online/library/history/sabin.html.

González-Fernández, A. y Díaz de Espada, F. (2011). César Milstein: 35 ańos de anticuerpos monoclonales. Inmunología, 30(1), 30-33. https://www.elsevier.es/es-revista-inmunologia-322-articulo-cesar-milstein-35-anos-anticuerpos-S0213962611700129.

Hamidi, A. y Bakker, W. (2012). Innovative IPV from attenuated Sabin poliovirus or newly designed alternative seed strains. Pharmaceutical Patent Analyst, 1(5), 589-599. https://doi.org/10.4155/ppa.12.70.

How Much Money Did Jonas Salk Potentially Forfeit By Not Patenting The Polio Vaccine? (9 de agosto de 2012). Forbes. https:/www.forbes.com/sites/ quora/2012/08/09/how-much-money-did-jonas-salk-potentially-forfeit-by-not-patenting-the-polio-vaccine/?sh=3eff862d69b8.

Intellectual Property Expert Group. (2021). Jonas Salk inventor of the polio vaccine. Why did he not patent his invention? https://www.ipeg.com/jonas-salk-inventor-of-the-polio-vaccine-could-you-patent-the-sun/.

Jiménez Nácher, B. (7 de mayo de 2021). ¿Genérico Covid? "Levantar las patentes no favorece ni a corto ni a medio plazo". La Información. https://www.lainformacion.com/asuntos-sociales/generico-covid-levantar-patentes-favorece-corto-medio-pazo/2837533/.

Kinsella, L. (2206). Patent and Penicillin. Mises Institute. https://mises.org/wire/ patent-and-penicillin. 
Kohler, G. y Milstein, C. (1975). Continuous cultures of fused cells secreting antibody of predetermined specificity. Nature, (256), 495-497.

Kreia, F. (29 de abril de 2021). 'Unprecedented achievement': who received the first billion COVID vaccinations? Nature. https:/www.nature.com/articles/ d41586-021-01136-2.

Lehtinen, L. y Rapela, M. A. (2021). COVID-19, Patentes y Vacunas: ¿Acceso o Transferencia de Tecnología? ElDial.com - Contenidos Juridicos, elDial DC2E02. https://www.eldial.com.

Medical Research Council. (1997). A missed opportunity? The patent saga. What is Biotechnology? https://www.whatisbiotechnology.org/index.php/exhibitions/ milstein/patents/The-monoclonal-antibody-patent-saga.

Miles, T. (21 de octubre de 2016). Polio vaccine makers failing to make enough doses - WHO experts. Reuters. https:/www.reuters.com/article/health-polio-idUSL8N1CR5UJ.

Ministerio de Salud. Argentina. (2021). Chau Polio. http://www.msal.gob.ar/index.php/component/content/article/46-ministerio/547-chau-polio.

Modlin, J. F. y Chumakov, K. (2020). Sabin Strain Inactivated Polio Vaccine for the Polio Endgame. The Journal of Infectious Diseases, 221(4), 504-505. https://doi.org/10.1093/infdis/jiz077.

Organización Mundial de la Salud. (2020). Listings of WHO's response to COVID-19. 29 June 2020 Statement. https:/www.who.int/news/item/29-06-2020-covidtimeline.

Organización Mundial de la Salud. (2021). Draft landscape and tracker of COVID-19 candidate vaccines. World Health Organization, 28 May 2021. https://www.who.int/publications/m/item/draft-landscape-of-covid-19-candidate-vaccines.

Organización Mundial del Comercio. (2 de octubre de 2020). Waiver from certain provisions of the TRIPs Agreement for the prevention, containment, and treatments of COVID-19. Communication from India and South Africa. Council for Trade-Related Aspects of Intellectual Property Rights. Documento IP/ C/W/669. https://docs.wto.org/dol2fe/Pages/SS/directdoc.aspx?filename=q:/ IP/C/W669.pdf\&Open=True.

Rapela, M. A. y Lehtinen, L. (2 de mayo de 2021). Covid-19, propiedad intelectual, vacunas y soberanía en Cuba. Perfil. https://www.perfil.com/noticias/ opinion/covid-19-propiedad-intelectual-vacunas-y-soberania-en-cuba.phtml.

Rapela, M. A. y Schötz, G. (2020). Covid-19, Derechos de Propiedad Intelectual y Licencias Obligatorias. La Ley, T. 2020-C, 1-6.

Rapley, R. (1995). The biotechnology and applications of antibody engineering. Mol Biotechnol, (3), 139-154. https://doi.org/10.1007/BF02789110.

Salk Institute for Biological Studies. (2021). About Jonas Salk. https://www.salk. edu/about/history-of-salk/jonas-salk/.

Smith, J. S. (1990). Patenting the Sun: Polio and the Salk Vaccine. Harper Collins. Suess, J. (10 de mayo de 2019). Our history: Sabin and Salk competed for sa- 
fest polio vaccine. Cincinnati Enquirer. https://www.cincinnati.com/story/ news/2019/05/10/our-history-albert-sabin-jonas-salk-competed-for-safest-polio-vaccine/1140590001/.

Tansey, E. M. (Ed.). (1997). Technology transfer in Britain: the case of monoclonal antibodies. Welcome Institute for the History of Medicine.

Universidad de Cambridge. (2002). César Milstein, Nobel Laureate and co-inventor of the hybridoma technique for the production of monoclonal antibodies, died this weekend on Sunday 24 October 2002. https://www.cam.ac.uk/news/c\%C3\%A9sar-milstein-1927-2002.

Vercesi, A. (2021). Rosario y las patentes de las vacunas. La Capital. https://www. lacapital.com.ar/cartas-lectores/rosario-y-las-patentes-las-vacunas-n2659505. html.

\section{Jurisprudencia citada}

Association for Molecular Pathology v. Myriad Genetics, Inc., 569 U.S. 576 (2013). https://supreme.justia.com/cases/federal/us/569/576/.

Diamond v. Chakrabarty, 447 U.S. 303 (1980). https://supreme.justia.com/cases/ federal/us/447/303/. 
